\title{
Rekindling Student Connection and Engagement: A Covid-Era Design Charrette
}

\author{
Hazal Gumus Ciftci ${ }^{*}$ William Nickley ${ }^{b}$, Sébastien Proulx ${ }^{c}$ \\ ${ }^{a}$ The Ohio State University \\ ${ }^{\text {b}}$ The Ohio State University \\ 'The Ohio State University \\ *Corresponding author e-mail: gumusciftci.1@osu.edu
}

\begin{abstract}
:
The last three semesters have been full of struggles, change, and adaptation due to the COVID-19 pandemic. As design educators, we are prone to adaptation and navigating through ambiguity, but our students still need to practice finding their own way. We, an industrial design program, realized there has been a disengagement and disconnection between our students due to the hybrid and online education environment forced on us by COVID-19. This situation inspired us to organize a vertical charrette with the goal of invigorating communication between our industrial design cohorts while strengthening ties with a local partner specializing in large-scale 3D printing. For two weeks, our students worked together to create "parklet" design concepts. As a result, fifteen concepts were generated and seven of them were selected by the producer to be partly or entirely manufactured, but more importantly students got to enjoy the studio spirit and a collaborative environment.
\end{abstract}

Keywords: Design charrette, design studio, professional collaboration, online design education

\section{Introduction}

In 2020, as the COVID-19 pandemic began, people in design schools, like people in educational settings all over the world, started to look for ways to inspire their students in online environments. We, an industrial design program, moved our courses online in the Spring of 2020, then continued to have hybrid and online studio courses in the following Fall semester. As 2020 ended, we observed a decline in student energy, interest, and engagement in our courses. This was especially noticeable with second-year students; they did not have much interaction with their peers and instructors, nor could they rely on well-established pre-COVID relationships within their cohort as third- and fourthyear students could. This started to worry us. 
As there seemed to be no end to the pandemic in sight, we decided to run an online design charrette in which students from all levels mingled. Concurrently, a local large-scale 3D printing company expressed their willingness to collaborate with our program. We, three industrial design instructors, gathered at the end of Autumn term to build and refine details of a "design charrette", which had to be online and had to allow our students to keep up with their other courses. According to Pernice (2013), design charrettes are "short, collaborative meeting(s) during which members of a team quickly collaborate and sketch designs." Therefore, we planned quick meetings to act as catalysts for our students to become energized and connected in the time of COVID-19. Since all design studios in our program were online during the Spring 2021 semester, we had to refine the approaches of a typical design charrette.

This paper explains the path we took while creating a vertical design charrette, how it worked, its tangible and pedagogical outcomes, the lessons we learned, and how we positioned our program as a safe harbor to build a robust learning community. We adapted a historically proven, pre-COVID approach for facilitating an unconventional expression of the design process (i.e., a design charrette) to recently popularized interaction platforms in education and professional practice in the COVID-era (e.g., video conferencing and digital browser-based whiteboard tools). After careful consideration and a planning period of three months, we were set to integrate the vertical design charrette in industrial design studio courses spanning three undergraduate student cohorts for the Spring 2021 term.

\section{The Path of a Virtual Design Charrette}

At the start of the Autumn 2020 semester, we were concerned about how to capture our students' attention and ensure the reach of our pedagogical goals, especially in hybrid/online studio courses. Our anxiety had increased as the term progressed due to online interaction fatigue (Wiederhold, 2020), lack of time to create fully developed online/hybrid courses, and disconnection between our students and instructors due to the lack of daily interactions. Stappers (2021) mentions the crucial need to engage students in online courses and given the fact that our program has a relatively small number of undergraduate students (forty-seven students in total) we decided to conduct a vertical charrette between the second, third and fourth-year industrial design student cohorts.

Şirin (2021) says online education proved the need for two types of educators: content creators and motivators. We took on the opportunity to invigorate and motivate our students by structuring an online charrette (i.e., content creation) while pushing students to proactively engage with professional designers and industry partners (i.e., motivation). We believe our efforts to align with what Smith $(2012$, p.2) says:

Collaboration and efficiency are at the center of this [design charrette] process, most often through a series of studio sessions or intense workshops.

The idea behind our decision to implement a charrette was to refresh our students' minds by having them interact with professionals and peers outside of their usual groups. We intended our vertical design charrette to also support our students' imagination and creativity, foster their bonds with each other, and allow them to express their ideas in a fast-paced, low-stakes, and versatile manner.

The reality of online education introduced us to Zoom fatigue, and one of the reasons for it is "videoconferencing programs are not completely synchronous... There is a slight delay between when a person performs an action and when the other participants are able to observe it" (Wiederhold, 2020). We took the evidence of online fatigue into consideration as we searched for and developed a more flexible structure that included synchronous and asynchronous modes of 
communication where our students could go at their own pace but with a greater responsibility to their peers.

\subsection{Design Studio Dynamics during COVID-19}

Debates around design and architecture studios and how they should be conducted have been going on for decades (Wojtoviz, 1995; Wang, 2010). Recent initiatives such as Future of Design Education ${ }^{1}$ and Design Education ${ }^{2}$ invite design educators, designers, and interested people to contribute to these conversations. Even before the pandemic, the need to update design education and channel new skills to build in the $21^{\text {st }}$ century was being sought. Meyer and Norman (2020, p.46-47) argue:

...Professions such as engineering, medicine, and business once faced similar issues. By careful study of themselves, they were able to reach consensus upon major changes in how they conducted their education. We believe now is the time for design to do the same.

With COVID-19, design education also has faced a dramatic change overnight. Instructors have been asked to develop online/ hybrid courses, find novel ways to produce quality education materials virtually, and keep students productive under extreme circumstances. Online education presented us, design educators, with a host of new challenges, not helped by our limited experiences conducting online courses or preparing for virtual modes of interaction.

Our studio activities suffered the most in this picture since there was not enough peer collaboration among students, interactions with materials, or even effective instructor-guided critique sessions. Miro $^{3}$ and Zoom ${ }^{4}$ had become fixtures in our virtual classrooms; by the end of the Autumn semester, 2020, students were not only familiar with the benefits of synchronous, group video conferencing (Zoom), but also with many of its limitations, among them the ineffectiveness of the Zoom platform in facilitating the type of interactive studio environment on which we rely.

\subsection{Logistics of The Online Charrette}

We started planning our charrette toward the end of Autumn Semester in December 2020. Meetings between instructors and IC3D, our industry partner, took place to decide on the details of our collaboration. IC3D sought to have credible and robust design concepts, while we as instructors sought to create an invigorating and engaging experience for students. We agreed on challenging our students to design a "parklet" - a temporary recreational place to foster community - targeting our school's courtyard. This also presented the opportunity to link the charrette with an ongoing campus initiative called the "Arts District" (The Ohio State University, 2021). Besides acting as a motivation for returning to campus, connecting the charrette with the "Arts District" supported our goal of creating a stronger community within our college. This partially hidden courtyard between the Hayes Hall and Hopkins Hall buildings presented our students with a challenge to rethink an oftenoverlooked space.

\footnotetext{
1 www.futureofdesigneducation.org

2 www.designeducation.com

3 www.miro.com

4 www.zoom.us
} 
Our department has historically leveraged strategic engagement with industry partners to contribute to our students' creativity and connect them with the non-academic world. Following this tradition, we reached out to several professional designers who expressed their willingness to act as design mentors for our students along with our industry partner's employees as 3D printing advisors.

Being online allowed us to shuffle the typical studio schedule which is normally constrained by room availability. We scheduled all industrial design studio courses at the same time for the Spring term to support the coordination and agility of instructors and to allow students to keep up with the rest of their classes. Second-year courses such as Materials \& Production Processes and Design Media realigned their course content with the charrette's theme before the event.

To monitor students' progress during the charrette, we asked for deliverables, which we called milestones, to be uploaded to a shared cloud folder. Uploaded files were not accessible to students, only to instructors. The first milestone was concept visualization and the second one asked for a summarized document of their discussions with IC3D.

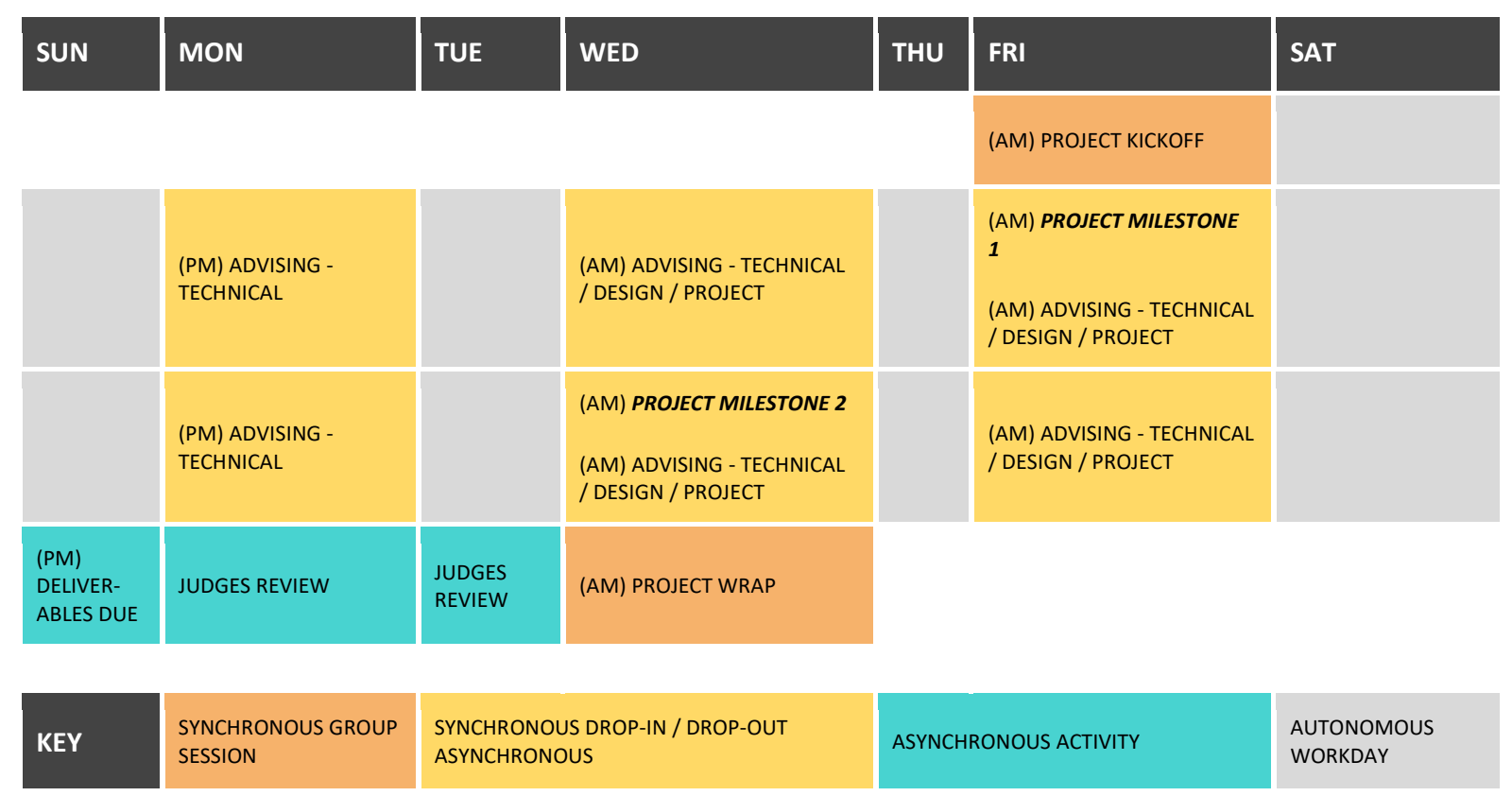

Table 1. Design Charrette Schedule

During scheduled advising sessions (Table 1), students, faculty, and industry partners connected through a browser-based video conference platform called Wonder. Wonder allowed our students and our partners to create discussion groups more organically than they could using Zoom. Within Wonder, discussion areas were organized into six themes, including one area for each of three advising topics (Project Advising, Technical Advising, Design Advising), a Team Chat area, a Coffee House, and Back-in-a-Minute area. When joining an emergent Wonder group, a participant entered a video conference environment where they could speak with and see others in the group and share their screen (Figure 1). 


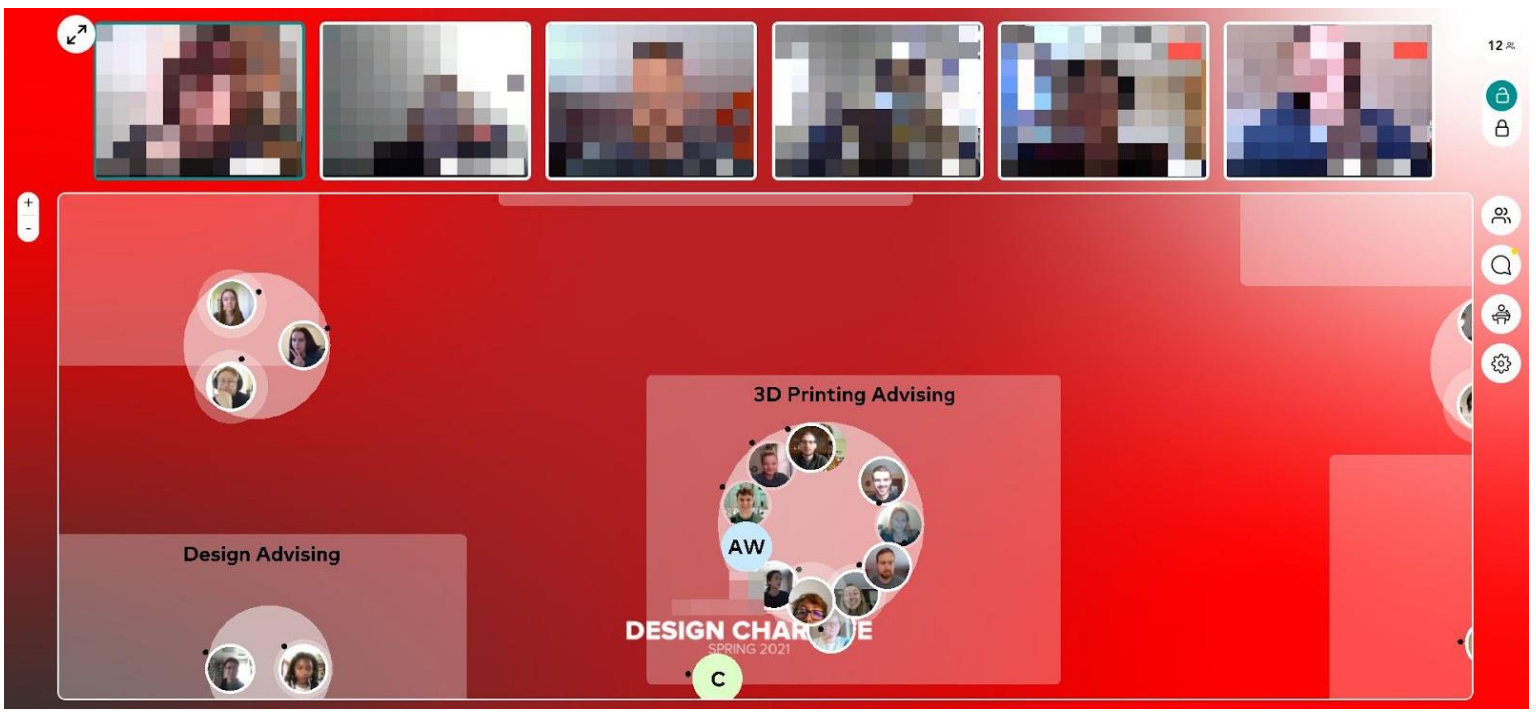

Figure 1. Screenshot from an advising session on Wonder; shown here are six video feeds from the 12 participants in an emergent group within the 3D Printing Advising area.

We realized that the technical advising (3D printing advising in Figure 1), led by two staff members at IC3D, was usually the most populated area. We observed that the above-mentioned Wonder thematic areas worked as expected since "participation means...come together in one location, exchange views and expertise, and from there forge new understandings in a generative and creative space" (Smith, 2012).

\subsection{Outcomes of the Charrette}

In their finalized concepts, students presented unique "parklet" concepts as temporary recreational places to foster community. Concepts considered how a partly hidden courtyard could be designed to serve as a dynamic place of gathering for students, faculty, and staff within the university communities. Our determined objectives for the charrette and stretch goals of our partner company follow (Table 2).

Each student team will design a temporary parklet concept to transform the Hayes Hall Courtyard. Concepts might address:

Shared space needs for individuals and communities (stakeholders)

Service offerings and experience

Products for individual or communal use

Products that are easy to disassemble and to store

Partnerships and collaborations that do or could occur in this

shared space

A "stretch goal" from a project sponsor

Parklet concepts could include elements such as furniture, space divisions, sculpture, and so on; elements may be physical, digital, virtual, or a blend.
Parklet elements make liberal use of large-scale 3D-printing 3D-printed elements use a modular architecture

3D-printed elements, including those that interface with non-3Dprinted elements, can be assembled and disassembled with minimal additional hardware

Furniture elements that uniquely showcase IC3D capabilities

Table 2. Design charrette objectives and stretch goals

After conducting research, students autonomously structured their own idea generation processes and developed parklet concepts (Figure $2 \& 3$ ). Concepts were evaluated for their account of the 
realities of potential users and the holistic characteristics of the target location. Of the fifteen student concepts presented, IC3D selected components from seven of them to later manufacture at full-scale.

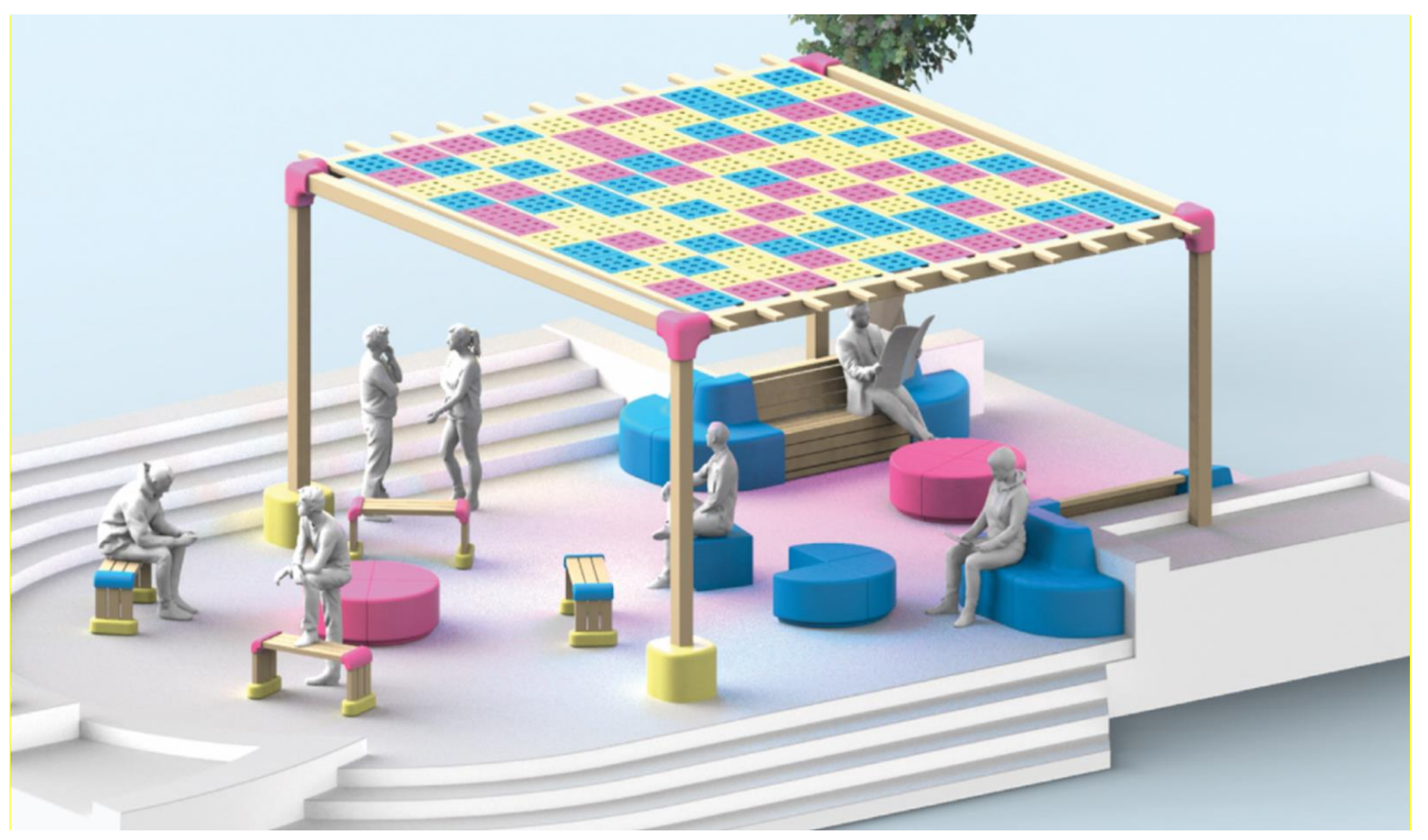

Figure 2. Student parklet concept "Afterhours" proposes the use of modular, 3D-printed components and lumber to form seating and a shade structure in an existing on-campus amphitheatre.

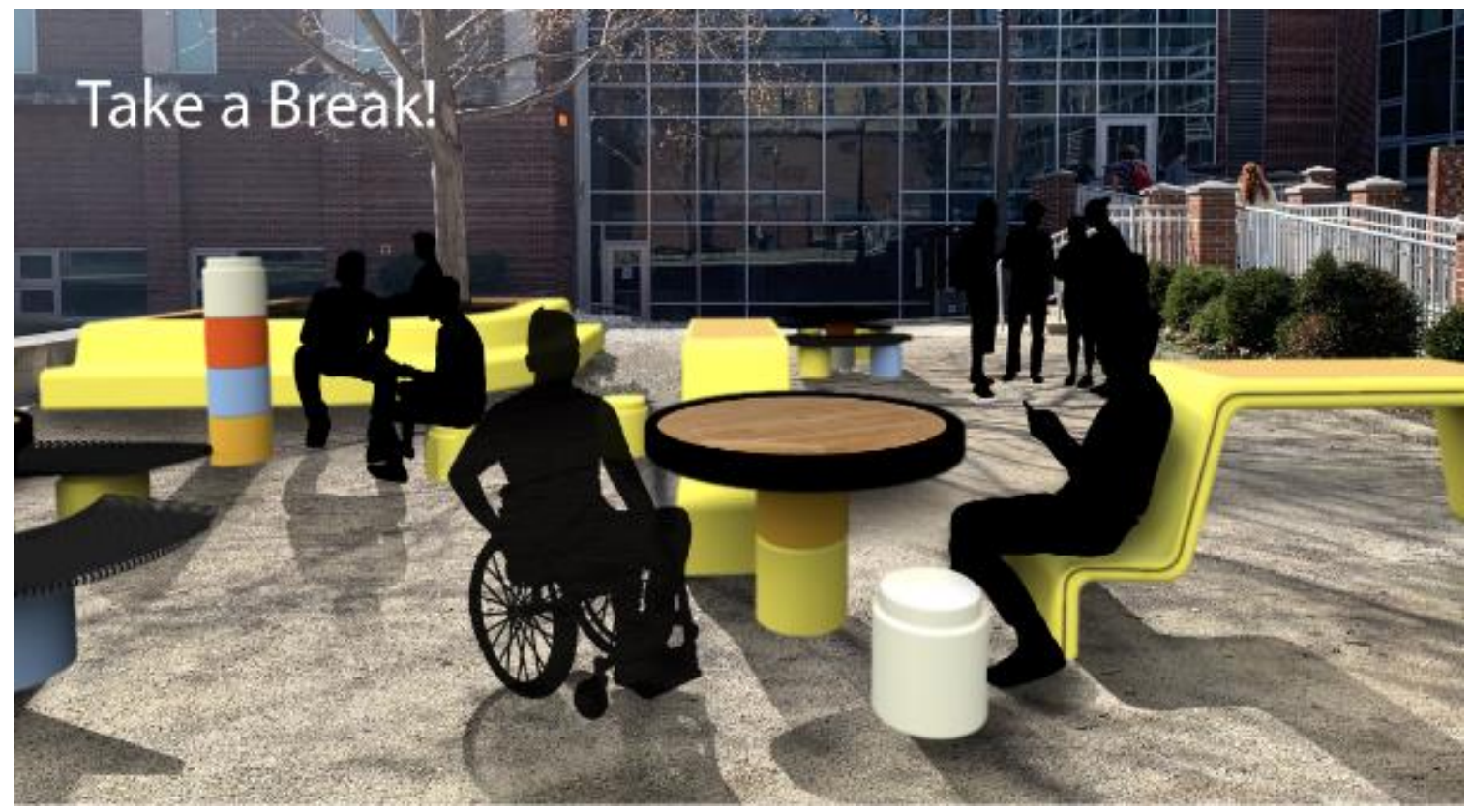

Figure 3. Student parklet concept "Take a Break" proposes modular sitting and standing areas to foster connection through collaboration and relaxation in an underutilized area of the courtyard. 
Right after the charrette and the announcement of accolades ${ }^{5}$, we randomly divided students into 3 groups - each faculty member led a debriefing session with students on Zoom. The general atmosphere was positive toward how we conducted the charrette. Along with the debriefing sessions, we asked our students to complete an online form to assess their peers, to provide feedback about their experiences, and to share their ideas about the charrette's structure.

Our students frequently cited how they enjoyed working together $(n=6)$ and the fun they had working in their group $(n=8)$. Evidently, the design charrette helped to create a stronger sense of community among the students which we hope will continue in the future.

\section{Lessons Learned}

We organized our design charrette to be online for our students and our industry partners during the COVID-19 pandemic compulsorily. This has given us a chance to consider changes for future events to build a continuous collaboration with potential mentors, industry partners, and more importantly to create a refreshing environment for our students who have been struggling with their school workload even prior to the pandemic. Additionally, we tweaked our usual design studio dynamics by not joining as design advisors but as project managers.

\subsection{Fostering Community is Worth the Time and Effort}

When we reflect on what we, instructors, have learned so far this year, facilitating effective online learning and fostering a virtual community are two important themes. By organizing the online design charrette, we aimed to include our second-year students -who have been mostly remote in the last fifteen months- in the wider community of industrial design students.

We observed situations in which lower-level students rose to the occasion by contributing effort and perspective to their team's parklet concepts. We saw an increase in second-year students' confidence in their design abilities when the course topics they were taking coincided with the charrette topics (e.g., placed-based design research, disruptive innovation, distributed and flexible manufacturing). Thus, we expect a more strategic alignment between lecture-based courses and future charette topics to provide our students, especially second year students, with a direct avenue to contribute to their teams' concepts.

Design professionals in the Columbus Metropolitan area have been willing to join our efforts to allow ideas from industry and academia to mingle. Comparing our past experiences with professional mentors to the design charrette we realized that the students were more proactive and our partners (both design professionals and the company employees) were at ease with their time in the online environment. Hence, we plan to have virtual collaborative events with the industry more often.

We believe our efforts of organizing an online design charrette for three months paid off because our students connected with one another, they interacted with design professionals, and they were able to design (and in near future to build) their parklet concepts for our wider community on campus.

\subsection{Challenges of Teamwork}

Our observations indicate the physical proximity of team members to one another as an issue for students working as a team. Although we did not ask teams to meet physically, some decided to

\footnotetext{
${ }^{5}$ All the concepts and accolades can be viewed at https://go.osu.edu/design charette 2021 gallery
} 
work together on-campus while maintaining social distance. However, when team members were out of the City of Columbus, planning times to collaborate was challenging for our students. In future years, surveying student accommodation to learn whether they are on-campus or off-campus would be helpful to create teams along with team-building exercises.

Lack of communication was an issue that came up in the survey results. However, this might be a result of constricted virtual interactions, or it could also be a reflection of team dynamics.

Fortunately, our students provided direct feedback in their survey responses about their strengths, the skills which they wanted to improve, and how the charrette could be improved.

\subsection{Navigating a Different Structure}

Undeniably, our students enjoyed interacting with students from other industrial design cohorts which was new to them - and they were open to learning from their peers. Another change we offered was our roles as instructors. We had limited our advising role to matters of coordination, and although it was difficult at times, we strongly believe that the results were successful (e.g., respectful to constraints, credible, manufacturable) and our students proved they were able to work with others in various positions (e.g., student peers, professional designers, instructors, 3D prototyping experts).

In our studio courses, we encourage constructive peer feedback, and having access to peers' work is a way for students to learn from others' experiences. During this charrette, there were few opportunities for teams to view others' work. The milestone submissions were only visible to the instructors, and we had an online whiteboard dedicated to the final deliverables. This time, we wanted to stir up the excitement and create a sense of secrecy, but we hope that we can host the next charrette in-person; we may use the preliminary submissions to gather peer and professional feedback.

\section{Conclusion}

The COVID-19 global pandemic has adversely impacted the health sector, social life, and economy; education is one of the widely impacted sectors, and our students feel behind, disconnected. We feel the educational system has been dysfunctional. Design education was thought to be less suitable for online interactions since most design courses make use of in-person and hands-on modes of instruction. We, as faculty of an industrial design program, acted on this challenging but promising opportunity to create more engaging virtual learning environments. We planned and conducted a vertical design charrette, virtually integrating a variety of stakeholders - a local 3D printing company, professional designers, design students from three cohorts, and design faculty. As a result, our students interacted with their peers and industry partners proactively. The parklet concepts that our students created also proved the timely integration of such a project to create a safe harbor for our community. Belonging to a department with over fifty years history, we would like to continue our efforts to foster bonds with our extensive alumni network; we see the design charrette as an annual catalyst for connecting design students and professionals, thus contributing to continued growth of our design community. 


\section{References}

The Ohio State University. (2021). The Arts District|The Ohio State University. Retrieved from https://www.osu.edu/the-ohio-state-university-environments/arts-district/

Meyer, M. W., \& Norman, D. (2020). Changing Design Education for the 21st Century. She Ji: The Journal of Design, Economics and Innovation, 6(1), 13-49.

Pernice, K. (2013, December 22). Design Charrettes and Team Sketching: 1/2 Inspiration, 1/2 Buy-in. Retrieved from https://www.nngroup.com/articles/design-charrettes/

Smith, N. D. (2012). Design charrette: A vehicle for consultation or collaboration?. In Proceedings,

Participatory Innovation Conference 2012. Swinburne University, Melbourne, Australia.

Stappers, P. J. (2021, February 10). C\&C X.1 Context \& Conceptualisation \& Corona. Retrieved April 2021, from https://vimeo.com/510592809

Şirin, S. (2021, April 21). S1E1: Nilay Örnek ile Yolculuk Nereye? Konuk: Selçuk Şirin. (N. Ornek, Interviewer)

Wang, T. (2010). A New Paradigm for Design Studio Education. The International Journal of Art and Design Education, pp. 173-183.

Wiederhold, B. (2020, July). Connecting Through Technology During the Coronavirus Disease 2019 Pandemic: Avoiding "Zoom Fatigue". Cyberpsychology, Behavior, and Social Networking, pp. 437438.

Wojtoviz, J. (1995). Virtual Design Studio. Hong Kong University Press. HK.

Author Bios:

Hazal Gumus Ciftci is a lecturer in the industrial design program at The Ohio State University. She holds a PhD in Design from Lancaster University and a Master of Science degree in Product/Service/System Design from Politecnico di Milano.

William Nickley is Assistant Professor in the Department of Design at The Ohio State University. He holds an MFA in Design and a BSD in Industrial Design from The Ohio State University. He researches social design practice as a member of the Ohio State DESIS Lab.

Sébastien Proulx is Associate Professor of Design, Coordinator for the industrial design major and Co-Director of the DESIS Lab at The Ohio State University. He holds a PhD in Design and a Master of Applied Science in Design and Complexity from the University of Montreal.

Acknowledgements: We would like to thank IC3D, Sean Svendsen, and Stephanie Owens for their time and support during the design charrette. 